\title{
Agricultural Landscape Dynamics and Its Response in Seasonal Vegetation Activities in the Loess Plateau, Northern Shaanxi, China
}

\author{
Zhengguo $\mathrm{Li}^{1,2, *}$, Peng Yang ${ }^{1,2}$, Yanglin Wang ${ }^{3}$, \\ Qingbo Zhou ${ }^{1,2}$, Huajun Tang ${ }^{1,2}$, and Hsiaofei Chang ${ }^{4}$ \\ ${ }^{1}$ Key Laboratory of Resources Remote Sensing and Digital Agriculture, Beijing 100081, China \\ ${ }^{2}$ Institute of Agricultural Resources and Regional Planning, \\ Chinese Academy of Agricultural Sciences, Beijing 100081, China \\ ${ }^{3}$ Department of Geography, Peking University, Beijing 100871, China \\ ${ }^{4}$ Research Center for Eco-Environmental Sciences, Chinese Academy of Sciences, \\ P.O. Box 2871, Beijing 100085, China \\ zhengguoli@caas.net.cn, (yangp, zhouqb, hjtang) @mail.caas.net.cn, \\ ylwang@urban.pku.edu.cn, lzg.123@263.net
}

\begin{abstract}
The ecological and environmental conditions in semiarid areas are closely linked to landscape dynamics. This study examined the seasonal vegetation activities of landscape classes and dynamics in the Loess Plateau in North Shaanxi Province, China. Landscape dynamics were studied by comparing Landsat images in 1987 and 2007, and classified as landscape transitions, landscape variations and unchanged landscape. The characteristics of seasonal vegetation activities, such as dates for onset-of-greenness, peaks, and onset-ofsenescence for landscapes were determined using Moderate Resolution Imaging Spectroradiometer (MODIS) 10-day vegetation index composite products (20022009). The landscape dynamics showed that some sloping croplands were converted to woodlands and grasslands. Vegetation activities responded diversely and seasonally to landscape classes and dynamics. Temporal analysis of the Normalized Difference Vegetation Index (NDVI) showed that the time of onsetof-greenness and onset-of-senescence were similar for all major landscape classes, while the time of peak vegetation activity was longer for tree than grass species. The analysis of seasonal vegetation activities and landscape dynamics indicated that seasonal vegetation activities were not only relative to landscape classes, but also affected by landscape dynamics.
\end{abstract}

Keywords: Agricultural Landscape, Landscape structure, Normalized Difference Vegetation Index (NDVI), The Loess Plateau of China.

\section{Introduction}

Serious soil erosion in Loess Plateau area of China and the increase in human disturbances in ecosystem have resulted in a range of ecological and land use

${ }^{*}$ Corresponding author.

D. Li and Y. Chen (Eds.): CCTA 2011, Part II, IFIP AICT 369, pp. 151-167, 2012.

(C) IFIP International Federation for Information Processing 2012 
problems, such as the depletion of land resources and the degradation of ecoenvironments. An urgent need for agricultural landscape and ecological planning appears to ensure the sustainable development of the Loess Plateau area (Fu et al., 2000). The formulation of policies relating to land use requires adequate understanding on the landscape dynamics. Considerable attention is paid, therefore, to the research and monitoring of the characteristics and trends of landscape and spatial changes (Chen et al., 2001; Fu et al., 2006). The findings are helpful to future landscape development and land use.

In this context, landscape structure, function and its dynamic changes constitute the fundamental contents of landscape ecology (Forman and Godron, 1986; Forman, 1995). Thus, change in spatial patterns is an important aspect of landscape dynamics, which will change landscape function (Turner and Ruscher, 1988; Turner, 1990a; Turner, 1990b). Landscape dynamics is always an active area of landscape ecology research (Li, 2000). Characterizing landscape dynamics and identifying its driving mechanism should be the pre-requisite to understand its ecological impact (Forman and Godron, 1986; Forman, 1995). Since the 1980s many methods have been proposed to quantify the mosaic patterns of landscapes (O'Neill et al., 1988; Turner, 1988; Forman, 1995). Among them, there is considerable interest in comparative landscape metrics with multi-date satellite imagery (Nagaike and Kamitani, 1999; Li, 1999); or investigating the mechanism of landscape dynamics by drive force analysis by which the change rules can be established (Wu et al., 2000) and simulated (Chang and $\mathrm{Wu}, 1998)$. However, few efforts have been made to evaluate landscape dynamics according to change intensity or range, to further explore their effect on ecological conditions.

Information on spatial and temporal dynamics of land cover is critical for regional and global change research (Senay and Elliott, 2000). Vegetation cover is an important ecological factor in semiarid and arid areas with great seasonal changes, due to functions such as intercepting rainfall, slowing runoff and preserving soil (Wang and Shao, 2001; Zhang et al., 2004). Research on applications of remotely sensed data for vegetation inventory and monitoring has focused on analysis of vegetation 'greenness' (Schwartz and Reed, 1999; Senay and Elliott, 2000), most often measured using the Normalized Difference Vegetation Index (NDVI). The NDVI is the most used vegetation index and has proved very useful in detecting vegetation change (Elmore et al., 2000), vegetation classification and deriving ecological parameters (Goward et al., 1985; Guo et al., 1999; Sobrino and Raissouni, 2000). The time series of NDVI may be analysed to generate a set of metrics that summarize the phenology of vegetation (Malingreau, 1986; Lloyd, 1990; Reed et al., 1994; Senay and Elliott, 2000; Michael and Graham, 2003).

Over the past 25 years or so, tremendous progress has been made for vegetation characterization by using the data from the Advanced Very High Resolution Radiometer (AVHRR) on board the National Oceanic and Atmospheric Administration (NOAA) meteorological satellites (Loveland et al., 1991). More recently, researchers have favoured higher spatial resolution products for regional scale vegetative studies (Michael and Graham, 2003). With the advent of the TERRA satellite, Moderate Resolution Imaging Spectroradiometer (MODIS) derived 
vegetation indices have been used for monitoring temporal changes associated with vegetation, particularly for large regions (Salomonson et al., 2001; Townshend and Justice, 2002; David and Gregory, 2004). In the Loess Plateau area, the agro-climatic system is highly seasonal with dry winters and wet summers. The growing season is defined by moisture availability for plant growth and determinate, obligate annual plant forms (Fu et al., 2000; Fu et al., 2006). Within this system, the time series of NDVI can characterize the temporal extent of the growing season and productive potential of agricultural landscape at the regional scale.

Capability to assess the relationship between landscape dynamics and vegetation seasonal changes is required for recognizing the critical factors and modelling the ecological condition changes in the Loess Plateau area (Xiao and Zhong, 1998; Fu et al., 2000). The vegetation response to landscape dynamics can reveal any benefits or damage to eco-functions of the regional ecosystem (Wang et al., 1999).

The landscape dynamics and its response in seasonal vegetation activities in the Loess Plateau area, China were analysed for a period of 20 years. The specific objectives were: (1) to investigate the dynamic changes in the agricultural landscape and identify the main driving factors; (2) to determine the periods for onset-ofgreenness, peaks and onset-of-senescence in each agricultural landscape, (3) to quantitatively and qualitatively assess the sensitivity of NDVI in discriminating landscape dynamics at the regional scale.

\section{Study Area and Materials}

\subsection{Study Area}

The study area was the northern part of Shaanxi Province, China between lat $35^{\circ} 21^{\prime} \mathrm{N}-$ $39^{\circ} 34^{\prime} \mathrm{N}$ and long $107^{\circ} 28^{\prime} \mathrm{E}-111^{\circ} 15^{\prime} \mathrm{E}$, in the middle part of the Loess Plateau. The area is $80,606 \mathrm{~km}^{2}$ and the main rivers include the Kuye, Wuding, Qingqian, Yan, Fenchuan Rivers and part of the Luo River (Fig. 1). The terrain has significant topographic variability with typical Loess hills and gully slopes with elevations of 400-1900 m. The area has a semi-arid continental monsoon climate, with cold winters and warm summers. During the past decades, agriculture has been the primary economic activity and income source in the area, and the most important land use change was the clearing of forestland and grassland for agriculture (Chen et al., 2001). The hilly topography, intensive precipitation and especially long-term extensive human activity (i.e. removal of the natural vegetation and farming-accelerated deterioration) have caused serious soil erosion (Fu et al., 2000; Fu et al., 2006). The present land cover and vegetation types include cropland, shrub, woodland (mainly in southern mountainous areas) and grassland. The main crops are potatoes (Solanum tuberosum), beans (Phaseolus vulgaris), maize (Zea mays) and millet (Panicum miliaceum). The woodland is dominated by introduced vegetation, mainly locust trees (Robinia pseudoacacia). In this area, little leaf peashrub (Caragana microphylla) is the most important shrub species. The grassland is mainly covered by annuals such as wheatgrass (Agropyron cristatum Gaertn.), sweet wormwood (Artemisia annua), annual fleabane (Erigeron annuus) and sandy needlegrass (Stipa glareosa). 


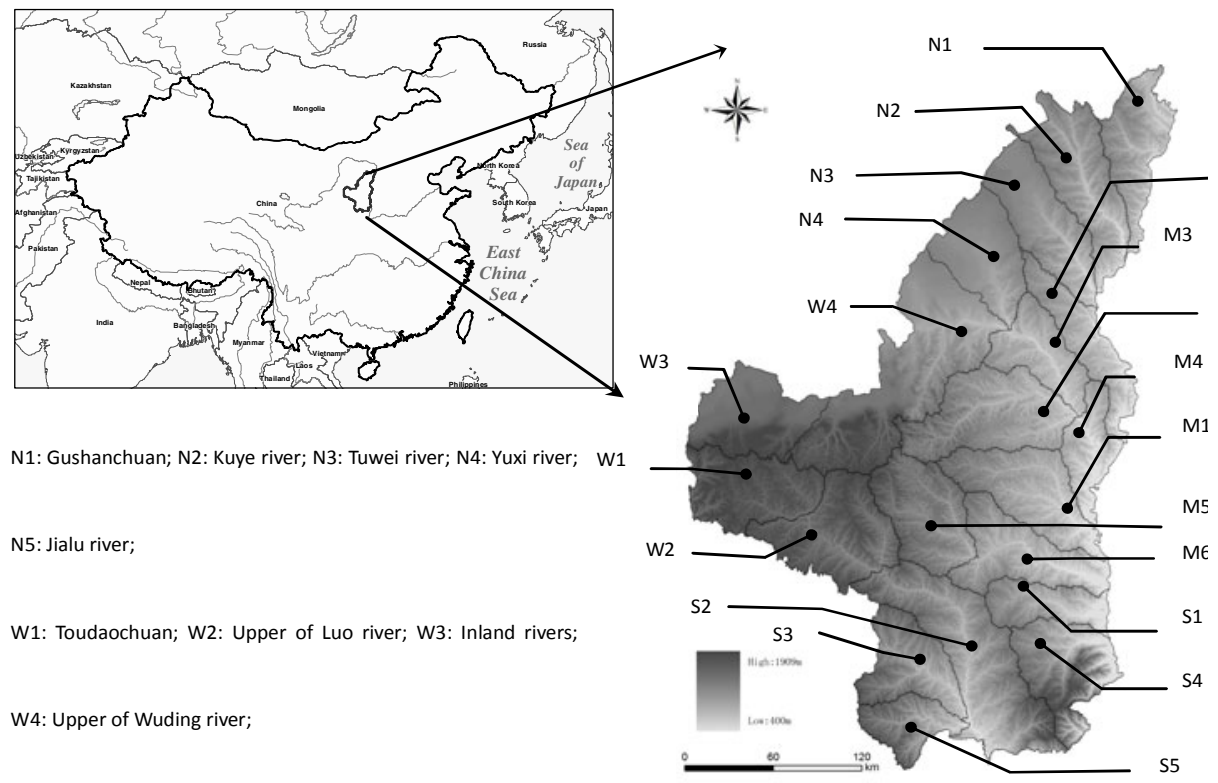

M1: Qingjian river; M2: Dali river; M3: Middle of Wuding river;

Fig. 1. Geographical location of study area and delineation of watersheds

\subsection{Data Used}

The landscape class data were derived from a series of Landsat-5 TM images acquired in 1987 and 2007. In total there were 12 images from each of the two time periods with the orbit sequence numbers 126-32, 34, 35 and 36; 127-33, 34, 35 and 36; and 128-34 and 35.

MODIS data were also used. MODIS 10-day vegetation index (VI) composite products in the period 2002-2009 were applied in the analyses. Due to limited availability of validated Landsat data coinciding with MODIS collects, the analysis was limited to 2007-2009, and to the major landscape classes( Table 1).

Table 1. Data source

\begin{tabular}{|c|c|c|}
\hline \multicolumn{2}{|l|}{ Data source } & \multirow{2}{*}{$\begin{array}{l}\text { Date/resolution } \\
1987.07 .29,2007.06 .02, \text { with a resolution of } 30 \mathrm{~m}\end{array}$} \\
\hline \multirow{3}{*}{ TM images } & $126-33 / 34 / 35 / 36$ & \\
\hline & $127-33 / 34 / 35$ & 1987.06.02, 2007.06.25, with a resolution of $30 \mathrm{~m}$ \\
\hline & $128-34 / 35$ & 1987.05.24, 2007.08.03, with a resolution of $30 \mathrm{~m}$ \\
\hline MODIS images & VI products (MOD13) & 10-Day composite from 2007 to 2009 , with a resolution of $0.5 \mathrm{~km}$ \\
\hline \multicolumn{2}{|c|}{ Topographic map of Shaanxi province (1:50000) } & Published by National Geomatics Center of China \\
\hline \multirow{2}{*}{\multicolumn{2}{|c|}{ Land use map of Shaanxi province }} & Made in 2000 by Institute of Geographical Sciences and Natural \\
\hline & & Resources Research, Chinese Academy of Sciences \\
\hline
\end{tabular}




\section{Methods}

\subsection{Data Pre-processing}

Data pre-processing used remotely-sensed image processing software packagesENVI 4.0, developed by RSI Company, and the geographical information system software ArcGIS 9.0, by ESRI Company. Prior to analysis, following atmospheric radiance calibration and initial geometric rectification of all the TM images using ENVI, a number of reference points were selected from a 1:50,000 scale topographic map. The TM images were rectified to a Gauss Kruger projection with a pixel resolution of $30 \mathrm{~m} \times 30 \mathrm{~m}$, by using nearest neighbour rules provided by ENVI, to ensure that the error was controlled in less than one-half pixel root mean square error. The MODIS products were also rectified to the Gauss Kruger projection by the above method, and resampled to $500 \mathrm{~m} \times 500 \mathrm{~m}$ pixel resolution. Finally, the data was masked so that the analysis was limited to the administrative area of the northern Shaanxi Province.

The MODIS VI products included maximum value composites of the NDVI and enhanced VI, as well as the corresponding red and near-infrared reflectance (band 1 and band 2) and quality assessment (QA) flags (Huete et al., 2002). Only NDVI values from the MODIS composite products were used, along with the VI Usefulness Index in the QA data set. Reflectance values of NDVI for dates with a Usefulness Index value lower than "good quality" were replaced by linearly interpolated values from the two closest dates with good, high or perfect quality. Finally, an iterative median smoother was used to retain peaks and eliminate valleys of the temporal NDVI curve.

\subsection{Classification of the 1987 and 2007 Landsat TM Images}

Landscape classification and mapping with remotely sensed data is a common technique, mainly based on the ability to reflect land surface and human activity information (Ichoku and Karnieli, 1996; Metternicht and Fermont, 1998). We used supervised maximum likelihood classification methods. The accuracy of the 1987 and 2007 images was assessed using ground data points not used in the classification process. The equal control point methods in ENVI were used with at least 30 points for each class. The overall accuracy assessment was checked separately for each image and accepted if the accuracy was $>80 \%$ (determined with 580 random checkpoints). After accuracy assessment, all images were clumped and vectorized using ENVI. These coverages were pre-processed to eliminate areas $<0.27$ ha (corresponding to 3 pixel $\times 1$ pixel) using ArcGIS for faster spatial analysis.

Landsat TM images (1987) were successfully classified for 11 landscape classes; settlements and sparse woodland were classified with a lower accuracy than other classes. However, this was acceptable as the overall classification accuracy is much higher $(87 \%)$ with the Kappa statistics value of 0.92 . The classification of images 
(2007) was also acceptable due to a higher overall classification accuracy (89\%) and Kappa values of 0.93 . Three main agricultural landscape classes were identified: cropland, woodland and grassland. A further subclassification of agricultural landscape was defined using the percentage of vegetation canopy and terrain characteristics (Table 2).

Table 2. Descriptions of landscape classes

\begin{tabular}{|c|c|c|}
\hline $\begin{array}{l}\text { Landscape } \\
\text { classes }\end{array}$ & Landscape subclasses & Description \\
\hline \multirow{3}{*}{ Cropland landscape } & irrigated cropland (Cropland-I) & cropland less than $15^{\circ}(\mathrm{AD} 15)$ \\
\hline & terrace cropland (Cropland-T) & $\begin{array}{l}\text { slope cropland more than } 15^{\circ} \text { (AD15) } \\
\text { and less than } 25^{\circ}(\mathrm{AD} 25)\end{array}$ \\
\hline & sloping cropland (Cropland-S) & slope cropland more than $25^{\circ}$ (AD25) \\
\hline \multirow{3}{*}{ Grassland landscape } & dense grassland (Grassland-D) & $75-100 \%$ grass cover \\
\hline & moderate dense grassland (Grassland-M) & $50-75 \%$ grass cover \\
\hline & sparse grassland (Grassland-S) & $<50 \%$ grass cover \\
\hline \multirow{3}{*}{ Woodland landscape } & dense woodland (Woodland-D) & $70-100 \%$ canopy cover \\
\hline & moderate dense woodland (Woodland-M) & $50-75 \%$ canopy cover \\
\hline & sparse woodland (Woodland-S) & $<50 \%$ canopy cover \\
\hline Residential landscape & settlements & residential areas \\
\hline Water landscape & wetland & natural and artificial lake, river \\
\hline
\end{tabular}

\subsection{Classifications of Landscape Dynamics}

According to the intensity or range of landscape changes, landscape dynamics were simplified to three typical landscape changes. First, the original landscape was replaced by a different landscape, causing transition of landscape classes. Second, the landscape class was unchanged while landscape subclass changed with varying landscape characteristics. Third, the landscape was unchanged because neither landscape class nor subclass changed.

The complexity of landscape dynamics was based on the landscape classification results in 1987 and 2007. The landscape classification scheme was defined as unchanged landscape, landscape variation and landscape transition. In detail; unchanged landscape meant the class and subclass of landscape remained as original; transition meant a shift of landscape class; and variation meant landscape class changed but subclass remained unchanged(Table 3 ). 
Table 3. Classifications of landscape dynamics

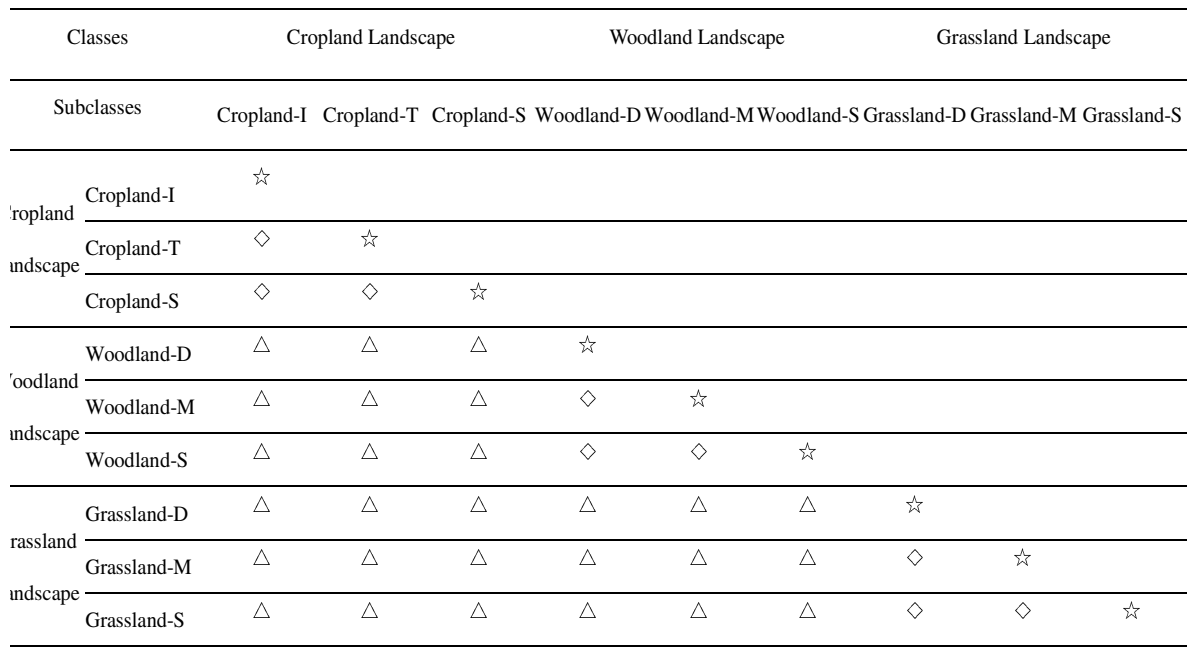

Notes: unchanged landscape, $\diamond$ landscape variation, $\triangle$ landscape transition.

\subsection{Characteristics of Seasonal Vegetation Activities}

A preliminary study on individual years indicated that although the relative magnitudes of the NDVI differed from year to year, partly due to different view angles and atmospheric conditions, the relative time periods for major vegetation activities could still be inferred (Senay and Elliott, 2000). It was anticipated that averaging of many years of data could eliminate sudden and unexplainable irregularities in the NDVI data (Michael and Graham, 2003). Thus, the source data were from the 3-year average 10-day maximum value MODIS-NDVI composites (2007-2009).

The key to defining seasonal characteristics is to identify the onset of the growing season. The method used was visual inspection of the seasonal NDVI curves accompanied by an evaluation of the difference between adjacent NDVI values (Senay and Elliott, 2000). Once the onset of the growing season was identified, additional seasonal characteristics were derived (Table 2). There were more than one local maximum NDVI values; two local maxima occurred, in the beginning and later part of the growing season. There were two families of seasonal characteristics: temporal and NDVI value. Temporal characteristics are time of onset of growing season (OnT), time of end of growing season (EndT), time of the first maximum NDVI (MaxT-1), and time of the second maximum NDVI (MaxT-2). NDVI characteristics are NDVI value at onset of growing season (OnV), NDVI value at end of growing season (EndV), the first maximum NDVI value (MaxV-1), and the second maximum NDVI value (MaxV-2). 
Table 4. Description of NDVI metrics calculated for the period 2007-2009

\begin{tabular}{|c|c|c|}
\hline Abbreviation & Definition & Metric \\
\hline OnT & $\begin{array}{l}\text { The period after which there was an increase of NDVI } \\
\text { values from a seasonally low value }\end{array}$ & $\begin{array}{l}\text { Starting date of NDVI high period } \\
\text { (onset-of-greenness) }\end{array}$ \\
\hline OnV & Value of NDVI at forwards intersection & NDVI at start of high period \\
\hline MaxT-1 & Time of the first maximum raw corrected NDVI & Date of the first maximum NDVI \\
\hline MaxV-1 & The first Maximum value of NDVI & The first maximum of NDVI \\
\hline MaxT-2 & Time of the second maximum raw corrected NDVI & Date of the second maximum NDVI \\
\hline $\mathrm{MaxV}-2$ & The second Maximum value of NDVI & The second maximum of NDVI \\
\hline EndT & the period after which a downward trend in NDVI began & End date of NDVI high period \\
\hline EndV & Value of NDVI at backwards intersection & $\begin{array}{l}\text { NDVI at end of high period } \\
\text { (onset-of- senescence) }\end{array}$ \\
\hline
\end{tabular}

\section{$4 \quad$ Results}

\subsection{Changes of the Landscape Pattern between 1987 and 2004}

According to the classified Landsat images between 1987 and 2007, landscape changes have occurred in composition and structure of the Loess Plateau area (Table 5). Cropland was the dominant landscape class in this area. The proportion of

Table 5. Landscape structure compositions in study area (1987-2007)

\begin{tabular}{|c|c|c|c|c|c|c|}
\hline \multirow{2}{*}{ Landscape type } & \multicolumn{3}{|c|}{ Area $\left(\mathrm{km}^{2}\right)$} & \multicolumn{3}{|c|}{ Ratio (\%) } \\
\hline & 1987 & 2004 & Difference & 1987 & 2004 & Difference \\
\hline Cropland-I & 322.4 & 403.0 & 80.6 & 0.4 & 0.5 & 0.1 \\
\hline Cropland-T & 24504.2 & 23375.7 & -1128.5 & 30.4 & 29.0 & -1.4 \\
\hline Cropland-S & 5803.6 & 5723.0 & -80.6 & 7.2 & 7.1 & -0.2 \\
\hline Woodland-D & 2015.2 & 2095.8 & 80.6 & 2.5 & 2.6 & 0.1 \\
\hline Woodland-M & 7173.9 & 7335.1 & 161.2 & 8.9 & 9.1 & 0.2 \\
\hline Woodland-S & 2579.4 & 2498.8 & -80.6 & 3.2 & 3.1 & -0.1 \\
\hline Grassland-D & 2257.0 & 2095.8 & -161.2 & 2.8 & 2.6 & -0.2 \\
\hline Grassland-M & 22730.9 & 23053.3 & 322.4 & 28.2 & 28.6 & 0.4 \\
\hline Grassland-S & 12171.5 & 12977.6 & 806.1 & 15.1 & 16.1 & 1.0 \\
\hline settlements & 322.4 & 806.1 & 483.6 & 0.4 & 1.0 & 0.6 \\
\hline wetland & 725.5 & 241.8 & -483.6 & 0.9 & 0.3 & -0.6 \\
\hline
\end{tabular}


cropland landscape decreased from 38 to $36.6 \%$; especially, there was a net decline of $1128.5 \mathrm{~km}^{2}$ in terrace cropland during 1987-2007. Grassland was also a significant landscape class, its area increased from 46.1 to $47.3 \%$, with a net increase of 806.1 $\mathrm{km}^{2}$ in sparse grassland. Overall, a large amount of cropland was transformed into woodlands and grasslands. Hence, over 1987-2004, there was a decrease in cropland and an increase in grassland and woodland.

\subsection{Landscape Dynamics and Landscape Classes}

Landscape dynamics among the major landscape classes, included landscape transition, variation and unchanged, were determined based on the classification of Landsat images. Certain landscape transitions or variations were observed and evaluated for each class (Table 6). For example, nearly $80.9 \mathrm{~km}^{2}(25.1 \%)$ of irrigated cropland was converted into other landscape classes; however, there were no landscape variations. A large amount of terrace cropland $\left(882.2 \mathrm{~km}^{2}\right)$ was transformed into grassland or woodland landscape, and $318.6 \mathrm{~km}^{2}$ of terrace cropland developed into irrigated cropland or degraded to sloping cropland. Of sloping cropland, a net area of $510.7 \mathrm{~km}^{2}$ shifted into grassland or woodland, and $116.1 \mathrm{~km}^{2}$ upgraded into irrigated or terrace cropland.

Of woodland landscape, the unchanged dense woodland was $1954.7 \mathrm{~km}^{2}$ (97.0\%), only $30.2 \mathrm{~km}^{2}$ was converted into other landscape classes, and a similar area of dense woodland degraded into medium or low coverage woodland. Most moderate dense woodland remained unchanged $(95.6 \%)$ and $1.0 \%$ changed into other woodlands, while $243.9 \mathrm{~km}^{2}(3.4 \%)$ shifted into other landscape classes. Of sparse woodland, there was an area of $123.8 \mathrm{~km}^{2}$ in landscape transitions and $15.5 \mathrm{~km}^{2}$ in variations.

Table 6. Landscape dynamics of landscape types (1987-2007)

\begin{tabular}{lcccccc}
\hline & \multicolumn{5}{c}{ Area $\left(\mathrm{km}^{2}\right)$} & \multicolumn{3}{c}{ Ratio $(\%)$} \\
\cline { 2 - 7 } Landscape type & Unchanged & landscape & Landscape & Unchanged & landscape & Landscape \\
& landscape & variation & transition & landscape & variation & transition \\
\hline Cropland-I & 241.5 & 0.0 & 80.9 & 74.9 & 0.0 & 25.1 \\
Cropland-T & 23303.5 & 318.6 & 882.2 & 95.1 & 1.3 & 3.6 \\
Cropland-S & 5176.8 & 116.1 & 510.7 & 89.2 & 2.0 & 8.8 \\
Woodland-D & 1954.7 & 30.2 & 30.2 & 97.0 & 1.5 & 1.5 \\
Woodland-M & 6858.2 & 71.7 & 243.9 & 95.6 & 1.0 & 3.4 \\
Woodland-S & 2440.1 & 15.5 & 123.8 & 94.6 & 0.6 & 4.8 \\
Grassland-D & 2011.0 & 2.3 & 243.8 & 89.1 & 0.1 & 10.8 \\
Grassland-M & 18116.5 & 3977.9 & 636.5 & 79.7 & 17.5 & 2.8 \\
Grassland-S & 7059.5 & 3700.1 & 1411.9 & 58.0 & 30.4 & 11.6 \\
\hline
\end{tabular}


Of grassland landscape, $2011 \mathrm{~km}^{2}(89.1 \%)$ of dense grassland remained unchanged, $243.8 \mathrm{~km}^{2}(10.8 \%)$ was converted to cropland and $2.3 \mathrm{~km}^{2}(0.1 \%)$ was degraded. A large amount of moderate dense grassland $3977.9 \mathrm{~km} 2(17.5 \%)$ was heavily degraded into low coverage, and $636.5 \mathrm{~km}^{2}(2.8 \%)$ changed into other landscapes. As for sparse grassland, an area of $1411.9 \mathrm{~km}^{2}$ was in landscape transitions and $3700.1 \mathrm{~km}^{2}$ in variations.

\subsection{Landscape Dynamics and Spatial Distribution}

The analysis of landscape composition in each watershed showed that the proportion of cropland landscape decreased gradually from north to south in the Loess Plateau area, while woodland and grassland obviously increased. Further landscape dynamics in watersheds were subsequently evaluated.

Table 7. Composition of landscape dynamics in watersheds

\begin{tabular}{|c|c|c|c|}
\hline \multirow[b]{2}{*}{ Watersheds } & \multicolumn{3}{|c|}{ Ratio (\%) } \\
\hline & $\begin{array}{l}\text { Unchanged } \\
\text { landscape }\end{array}$ & $\begin{array}{l}\text { landscape } \\
\text { variation }\end{array}$ & $\begin{array}{c}\text { Landscape } \\
\text { transition }\end{array}$ \\
\hline Gushan Chuan & 98.8 & 0.2 & 1.0 \\
\hline Kuye River & 86.9 & 7.4 & 5.7 \\
\hline Tuwei River & 78.5 & 6.2 & 15.3 \\
\hline Yuxi River & 82.1 & 4.6 & 13.3 \\
\hline Wuding River (upper) & 72.4 & 18.2 & 9.4 \\
\hline Wuding River (middle ) & 79.4 & 19.4 & 1.2 \\
\hline Wuding River (lower) & 94.3 & 1.5 & 4.2 \\
\hline Jialu RIver & 83.9 & 13.1 & 3.0 \\
\hline Dali River & 83.2 & 12.6 & 4.2 \\
\hline Toudao Chuan & 60.6 & 36.9 & 2.5 \\
\hline Qingqian River & 84.4 & 11.6 & 4.0 \\
\hline Yan River (upper) & 81.1 & 17.8 & 1.1 \\
\hline Yan River (lower) & 86.8 & 9.3 & 3.9 \\
\hline Luo River (upper) & 82.1 & 17.1 & 0.8 \\
\hline Luo River (middle) & 89.1 & 4.1 & 6.8 \\
\hline Yunyan River & 98.2 & 0.1 & 1.7 \\
\hline Hulu River & 92.4 & 4.4 & 3.2 \\
\hline Shiwang River & 96.2 & 1.0 & 2.8 \\
\hline Ju River & 97.7 & 1.2 & 1.1 \\
\hline Continental watersheds & 76.7 & 4.1 & 19.2 \\
\hline
\end{tabular}


The landscape classes in the north, where the classes were cropland and grassland, such as in the watersheds of Gushan Chuan River, the Kuye River and the middle reaches of the Wuding River, generally did not change (Table 7). In the middle area, the variations within landscape classes were significant; in Toudao Chuan River (36.9\%), the upper $(18.2 \%)$ and middle $(19.5 \%)$ reaches of the Wuding River, the upper $(17.8 \%)$ reaches of the Yan River and the upper $(17.1 \%)$ reaches of the Luo River, where the dominant landscape classes were dense and moderate dense grassland. Landscape transitions occurred mainly in the northwest, such as the continental watersheds (19.2\%), Tuwei $(15.3 \%)$ and Yuxi Rivers (13.3\%), where the landscape classes were mainly sparse grassland and sloping cropland. In the south, where woodland and grassland were the major landscape classes, almost no landscape transition took place; such as the watersheds of the upper reaches of the Luo $(0.8 \%)$, $\mathrm{Ju}(1.1 \%)$, Yunyan (1.7\%), Shiwang (2.8\%) and Hulu (3.2\%) Rivers.

\subsection{Seasonal Vegetation Activities of Landscape Subclasses}

Based on temporal plots of the 3-year average NDVI, the seasonal vegetation activities (onset, peak and senescence) of the various landscape subclasses were determined. For each landscape subclass, onset-of-greenness usually occurred about 15 April (Table 8). The peak-of-greenness occurred at different periods for different subclasses. The irrigated cropland was the first cropland to peak at the end of May; this was expected since this subclass was dominated by winter wheat. MaxT-1 occurred on approximately 15 July for terrace and sloping cropland, sparse woodland, moderate dense and sparse grassland; for dense woodland and grassland, moderately dense woodland, it occurred around 15 May. MaxT-2 was about 5 September for all cropland, sparse woodland, moderate dense and sparse grassland; and on about 25 September for dense and moderate dense woodland and dense grassland. Onset-ofsenescence was about 25 October for all the subclasses.

Table 8. Summary of vegetation activity based on MODIS data (2007-2009)

\begin{tabular}{lcccccccc}
\hline Landscape class & OnT & OnV & MaxT-1 & MaxV-1 & MaxT-2 & MaxV-2 & EndT & EndV \\
\hline Cropland-I & $4 / 15$ & 13.5 & $5 / 25$ & 41.2 & $9 / 5$ & 55.3 & $10 / 25$ & 48.3 \\
Cropland-T & $4 / 15$ & 6.1 & $7 / 15$ & 34.5 & $9 / 5$ & 40.3 & $10 / 25$ & 30.9 \\
Cropland-S & $4 / 15$ & 8.6 & $7 / 15$ & 39.6 & $9 / 5$ & 43.8 & $10 / 25$ & 33.8 \\
Woodland-D & $4 / 15$ & 18.3 & $5 / 15$ & 62.2 & $9 / 25$ & 61.2 & $10 / 25$ & 57.3 \\
Woodland-M & $4 / 15$ & 14.2 & $5 / 15$ & 47.5 & $9 / 25$ & 53.1 & $10 / 25$ & 49.7 \\
Woodland-S & $4 / 15$ & 11.9 & $7 / 15$ & 50.6 & $9 / 5$ & 50.5 & $10 / 25$ & 44.2 \\
Grassland-D & $4 / 15$ & 16.3 & $5 / 15$ & 58.6 & $9 / 25$ & 59.8 & $10 / 25$ & 56.6 \\
Grassland-M & $4 / 15$ & 8.6 & $7 / 15$ & 39.9 & $9 / 5$ & 43.5 & $10 / 25$ & 36.0 \\
Grassland-S & $4 / 15$ & 7.5 & $7 / 15$ & 33.7 & $9 / 5$ & 38.3 & $10 / 25$ & 30.0 \\
\hline
\end{tabular}


Landscape subclasses are compared in Table 8. All landscape subclasses in the Loess Plateau area had a high degree of variability in NDVI. Average NDVI values ranged from 6.1 for terrace cropland to 18.3 for dense woodland at the OnT. Furthermore, NDVI ranged from 33.7 and 38.3 for sparse grassland to 62.2 and 61.2 for dense woodland at the MaxT-1 and MaxT-2, respectively. Similarly, the NDVI values varied from 30.0 to 57.3 at the EndT.

\subsection{Seasonal Vegetation Activity of Landscape Dynamics}

The temporal plots of NDVI showed that vegetation activities responded diversely and seasonally to landscape classes and dynamics. As for unchanged landscape,
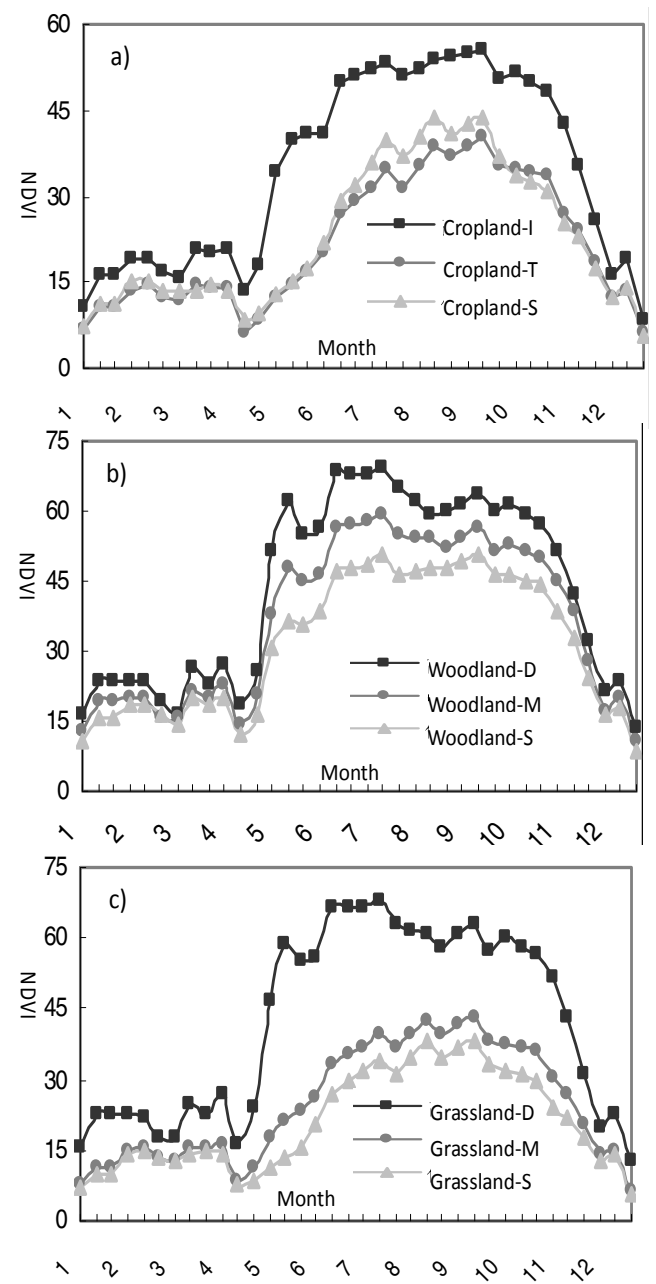

Fig. 2. vegetation seasonal activities of unchanged landscape 
landscape subclasses in the Loess Plateau area could be categorized into two general groups of seasonal vegetation activities. The first group was irrigated cropland (Fig. 2a), dense and moderate dense woodland (Fig. 2b) and moderate dense grassland (Fig. 2c), which had an extended period between MaxT-1 and MaxT-2. The group could be influenced by the physiology of trees. The dense grassland and irrigated cropland subclasses also contained significant tree species inclusions (i.e. the MODIS pixels in a predominantly pasture or crop area might include signals from nearby forest). The second group was generally dominated by grass species. Sloping and terrace cropland (Fig. 2a), moderate dense and sparse grassland (Fig. 2c) had a relatively short period between MaxT-1 and MaxT-2. This could be due to these subclasses being mainly distributed in the northwest of the Loess Plateau area where rainfall is relatively low with a semi-arid climate.
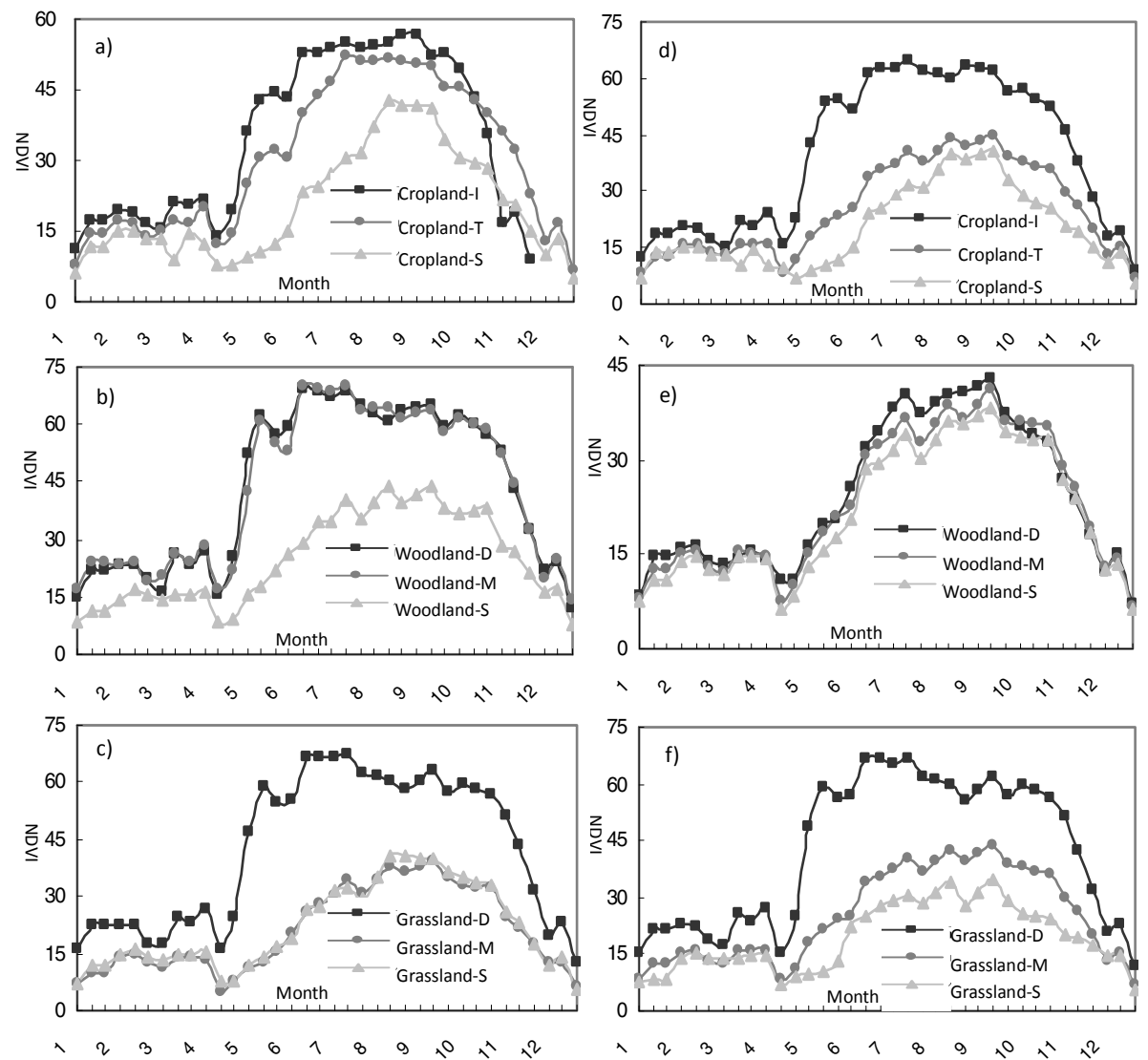

Fig. 3. Vegetation seasonal activities of landscape variations (left) and transitions (right) 
Similar rules could be found in landscape variations. Differing to other croplands, the seasonal vegetation activities in irrigated cropland were characterized by higher maximum NDVI values at MaxT-1 and MaxT-2, shorter renewal period between OnT and MaxT-1, much more extended growing period between MaxT-1 and MaxT-2 (Fig. 3a). Similarly, the dense and moderate dense woodlands (Fig. 3b) and dense grasslands (Fig. 3c) had almost the same characteristics as each other of vegetation seasonal activities, while the sparse woodlands (Fig. 3b), moderate dense and sparse grasslands (Fig. 3c) had the opposite features with lower maximum NDVI values at MaxT-1 and MaxT-2, much longer renewal period between OnT and MaxT-1, shorter growing period between MaxT-1 and MaxT-2

Compared with irrigated cropland in landscape variations, there was a similar temporal pattern of seasonal vegetation activities in landscape transitions (Fig. 3d). However, the terrace and sloping croplands had lower maximum values of NDVI, longer renewal periods and shorter growing periods (Fig. 3d). Especially, MaxT-1 for these two subclasses was two months later than for irrigated cropland. At the same time, all woodlands converted from other landscape classes had much lower maximum NDVI values and shorter growing seasons than other woodlands (Fig. 3e). All dense grasslands in various landscape dynamics had high maximum values of NDVI and extended growing seasons (Fig. 3f), while other grasslands in landscape transitions and variations had the low maximum and short growing season

\section{Discussion}

The dynamics of landscape classes were identified by repeated satellite images coupled with GIS analyses of 1987 and 2007. The proportion of terrace and sloping cropland decreased. The proportion of moderate dense and sparse grassland, the dense and moderate dense woodland landscape increased. The quantitative evidence showed that some sloping croplands were converted to woodlands and grasslands in the past decades. Presumably, this is due to structural adjustment of the agricultural sector, the initiation of Chinese Family Planning Policy, the increase in regional income in recent years and implementation of large-scale eco-environment conservation programmes (e.g. the Grain-for-Green Programme in 1999). From an ecological viewpoint, the present landscape structure and pattern is more sustainable than the former.

In semiarid and arid areas, vegetation has significant ecological functions, such as soil and water conservation and providing habitats for all life forms. Vegetation activities (onset, peaks and senescence) could directly reflect soil resistance to erosion and the temporal pattern of water use. Most of all, the identification of two growing season peaks could be important to identify water use patterns of different agricultural landscape types. The period between the second peak and senescence could signify a gradual decrease in water use, while the period after senescence a rapid decline in evapotranspiration (Senay and Elliott, 2000).

The findings suggest that the spatial correspondence of MODIS and Landsat data sets was robust, and the combination of the two data sets to characterize spatial heterogeneity and temporal dynamics of vegetation was justified. This research has 
shown that MODIS NDVI data has the potential to determine periods of important vegetative activities and relative 'greenness' magnitudes that can influence major energy and mass flux processes at regional scales.

\section{Conclusion}

On the regional scale, landscape compositions in the northern watersheds were mainly grassland and mixed cropland-grassland landscape, while in the southern watershed, landscape compositions mainly included mixed cropland-woodland and mixed woodland-grassland. Correspondingly, the vegetation cover ranged from low to high, which reflected the spatial pattern of vegetation cover resulting from natural forces and human activities on the macro regional scale.

Using a 3-year average of MODIS NDVI data, the temporal analysis of NDVI values showed that the onset-of-greenness (middle April) and onset-of-senescence (late October) were at similar times for all major landscape classes. The main difference among the classes was the NDVI magnitude in the period between onsetof-greenness and onset-of-senescence. Generally, the length of time for the peak vegetation activity (i.e. MaxT-1 to MaxT-2) was longer for tree than grass species.

The ranking of landscape subclasses in seasonal vegetation activities indicated that moderate dense grassland had landscape subclasses in two general groups. It is important to note that the moderate dense grassland was by far the dominant landscape in almost all watersheds. Landscape subclasses with seasonal average NDVI values less than moderate dense grassland included: all croplands, sparse woodland and sparse grassland; landscape subclasses with NDVI values larger than included dense and moderately dense woodland and dense grassland.

Taking landscape dynamics into account, the peak vegetation activity in unchanged landscapes was from high to low in the following sequence: dense and moderate dense woodland $>$ dense grassland $>$ sparse woodland and irrigated cropland $>$ moderate dense grassland $>$ terrace cropland $>$ sloping cropland and sparse grassland. For landscape variations, the sequence was: dense and moderate dense woodland and irrigated cropland > dense grassland, sparse woodland and terrace cropland > moderate dense grassland $>$ sparse grassland and sloping cropland. For landscape transitions, the sequence was: irrigated cropland $>$ dense grassland $>$ dense woodland, terrace cropland and moderate dense grassland $>$ sloping cropland $>$ moderate dense, sparse woodland and sparse grassland.

By analysing the relationships among the seasonal vegetation activities, landscape types and dynamics, it was evident that seasonal vegetation activities were not only relative to landscape classes, but also affected by landscape dynamics (e.g. landscape transitions and variations). Therefore, more attention should be paid to landscape spatial structure and temporal dynamics for the ecological recovery and construction in the Loess Plateau of North Shaanxi.

Acknowledgements. The initial and ongoing research support was financially supported by National Basic Program of China (973 Program, 2010CB951502), by 
the National Natural Science Foundation of China (No. 40930101, No. 41001381 and 41001246), and by the Ministry of Finance of China through Non-profit National Research Institute (IARRP-2011-015). All persons and institutes who kindly provide their data available for this analysis are greatly appreciated.

\section{References}

Chang, X.L., Wu, J.G.: Spatial analysis of pattern of sandy landscape in Kerqin, inner Mongolia. Acta Ecologica Sinica 18(3), 225-230 (1998) (in Chinese, with English abstract)

Chen, L.D., Wang, J., Fu, B.J., Qiu, Y.: Land use change in a small catchment of northern Loess Plateau, China. Agriculture Ecosystem Environment 86, 163-172 (2001)

David, B.L., Gregory, P.A.: Cropland distributions from temporal unmixing of MODIS data. Remote Sensing of Environment 93(1), 412-422 (2004)

Elmore, A.J., Mustard, J.F., Manning, S.J., Lobell, D.B.: Quantifying vegetation change in semiarid environments: Precision and accuracy of spectral mixture analysis and the Normalized Difference Vegetation Index. Remote Sensing of Environment 73(1), 87-102 (2000)

Forman, R.T.: Land Mosaics-The Ecology of Landscapes and Regions. Cambridge University Press, Cambridge (1995)

Forman, R.T., Gordron, M.: Landscape Ecology. Wiley, New York (1986)

Fu, B.J., Chen, L.D.: Agricultural landscape spatial pattern analysis in the semi-arid area of the Loess Plateau, China. Journal of Arid Environment 44, 291-303 (2000)

Fu, B.J., Zhang, Q.J., Chen, L.D., Zhao, W.W., Gulinck, H., Liu, G.B., Yang, Q.K., Zhu, Y.: Temporal change in land use and its relationship to slope degree and soil type in a small catchment on the Loess Plateau of China. Catena 65(1), 41-48 (2006)

Goward, S.N., Tucker, C.J., Dye, D.J.: North American vegetation patterns observed with the NOAA-7 advanced very high resolution radiometer. Vegetation 64, 3-14 (1985)

Huete, A., Didan, K., Miura, T., Rodriguez, E., Gao, X., Ferreira, L.: Overview of the radiometric and biophysical performance of the MODIS vegetation indices. Remote Sensing of Environment 83(1-2), 195-213 (2002)

Ichoku, C., Karnieli, A.: A review of mixture modeling techniques for sub pixel land cover estimation. Remote Sensing Review 13, 161-186 (1996)

Lloyd, D.: A phenological classification of terrestrial vegetation cover using shortwave vegetation index imagery. International Journal of Remote Sensing 11, 2269-2279 (1990)

Li, X.Z.: Assessment of land use change using GIS: A case study in the Uanos de Orinoco. Wagemigen University Press, Wagemigen (1999)

Li, X.Z.: The focus and front of landscape ecology development from the review of 15th USA annual landscape ecology conference. Acta Ecologica Sinica 20(6), 1113-1115 (2000) (in Chinese, with English abstract)

Loveland, T.R., Merchant, J.W., Ohlen, D.O., Brown, J.F.: Development of a land-cover characteristics database for the conterminous US. Photogrammetric Engineering and Remote Sensing 57, 1453-1463 (1991)

Metternicht, G., Fermont, A.: Estimating erosion surface features by linear mixture modeling. Remote Sensing Environment 64, 254-265 (1998) 
Malingreau, J.P.: Global vegetation dynamics: satellite observations over Asia. International Journal of Remote Sensing 9, 1121-1146 (1986)

Michael, J.H., Graham, E.D.: Estimating spatio-temporal patterns of agricultural productivity in fragmented landscapes using AVHRR NDVI time series. Remote Sensing Environment 84, 367-384 (2003)

Nagaike, T., Kamitani, T.: Factors affecting changes in landscape diversity in rural areas of the Fagus crenata forest region of central Japan. Landscape Urban Planning 43, 209-216 (1999)

O’Neill, R.V., Hunsaker, C.T., Timmins, S.P., Jackson, B.L., Jones, K.B., Riitters, K.H., Wickham, J.D.: Scale problems in reporting landscape pattern at the regional scale. Landscape Ecology 11, 169-180 (1996)

Reed, B.C., Brown, J.F., Vander Zee, D., Loveland, T.R., Merchant, J.W., Ohlen, D.O.: Measuring phenological variability from satellite imagery. Journal of Vegetation Science 5, 703-714 (1994)

Salmonson, V.V., Guenther, B., Masuoka, E.: A summary of the status of the EOS terra mission Moderate Resolution Imaging Spectroradiometer (MODIS) and attendant data product development after one year of on-orbit performance. In: IEEE 2001 International Geoscience and Remote Sensing Symposium, CDROM, July 9 -13 (2001)

Schwartz, M.D., Reed, B.C.: Surface phenology and satellite sensor-derived onset of greenness: an initial comparison. International Journal of Remote Sensing 20(17), 3451-3457 (1999)

Senay, G.B., Elliott, R.L.: Combining AVHRR-NDVI and landuse data to describe temporal and spatial dynamics of vegetation. Forest Ecology and Management 128(1), 83-91 (2000)

Sobrino, J.A., Raissouni, N.: Toward remote sensing methods for land cover dynamic monitoring: application to Morocco. International Journal of Remote Sensing 21(2), 353366 (2000)

Townshend, J., Justice, C.: Towards operational monitoring of terrestrial systems by moderateresolution remote sensing. Remote Sensing of Environment 83(1-2), 351-359 (2002)

Tunner, M.G.: Landscape changes in nine rural countries in Georgia. Photogrammetric Engineering and Remote Sensing 56(3), 379-386 (1990a)

Turner, M.G.: Spatial and temporal analysis of landscape patterns. Landscape Ecology 4(1), 21-30 (1990b)

Turner, M.G., Ruscher, C.L.: Changes in landscape patterns in Georgia, USA. Landscape Ecology 1(4), 241-251 (1988)

Wang, Y.L., Zhao, Y.B., Han, D.: The spatial structure of landscape eco-systems: concept, indices and case studies. Advance in Earth Sciences 14(3), 235-241 (1999) (in Chinese, with English abstract)

Wu, J.G., Jelinski, D.E., Luck, M., Tueller, P.T.: Multiscale Analysis of Landscape Heterogeneity: Scale Variance and Pattern Metrics. Geographic Information Sciences 6(1), 6-19 (2000)

Xiao, D.N., Zhong, L.S.: Ecological Principles for landscape classification and evaluation. Journal of Applied Ecology 9(2), 217-221 (1998); (in Chinese, with English abstract)

Zhang, Q.J., Fu, B.J., Chen, L.D., Zhao, W.W., Yang, Q.K., Liu, G.B., Gulinck, H.: Dynamics and driving factors of agricultural landscape in the semiarid hilly area of the Loess Plateau, China. Agriculture Ecosystem Environment 103, 535-543 (2004) 